\title{
Educación y liberalismo institucionista durante la restauración canovista: José Castillejo
}

\author{
Antonio M. López García
}

\begin{abstract}
RESUMEN
Si el krausismo y la Institución Libre de

Enseñanza fueron una laguna en medio del páramo que presentaba la educación en la España decimonónica, su discípulo Jose Castillejo Duarte (1877-1945) representó el engarce cultural con Europa de la España de la

Restauración tardía, sumida en una

grave crisis política y económica durante la segunda década del siglo xx. Sólo su trabajo abnegado, unido a su espíritu liberal, tolerante $y$ austero, fuertemente influenciado por el institucionismo de Giner de los Ríos, podía conseguir, con unos mínimos apoyos económicos y políticos, un

éxito tan mayúsculo como el que supuso la intelectualidad española de la I/ República, que alcanzó las cotas más altas de reconocimiento internacional.

PALABRAS CLAVE Educación. Restauración. Intelectuales. Institucionismo. Krausismo.

ABSTRACT

If krausism and «Institución Libre de Enseñanza" were a blank on the plateau of decimononic Spanish educatión, his disciple José Castillejo Duarte (1877-1945), represented a cultural hook to the Spanish late Restoration in Europe, immersed in a serious politic and economic crisis in the secon decade of the Xxc. Only hard work, mingled with his liberal thinking, tolerant and austere, highly influenced by Giner de los Rios could reach such a success with minimal economic and political support, resulting in the intelectuality of the Spanish second Republic, reaching the highest international prestige.

\section{KEY WORDS}

Education. Restoration. Intelectuals. Institutionism. Krausism.
\end{abstract}




\section{INTRODUCCIÓN}

José Castillejo Duarte es un personaje tan extraordinariamente interesante e importante como lamentablemente desconocido. Dentro de lo que es la vida y la obra de este gran intelectual sobresalen dos facetas: en primer lugar, la que sería su principal ocupación y preocupación, donde destacó sobremanera y a la que dedicó su vida, que es la educación y su labor al frente de la Junta para Ampliación de Estudios (JAE); en segundo lugar su pensamiento político, por el que es menos conocido si cabe, tal vez por su manifestación tardía y, seguro, por su propio deseo. Ambas actividades supusieron que en el tramo final de su vida tuviera que pasar por situaciones comprometidas en extremo.

\section{JOSE CASTILLEJO. UNA RESEÑA BIOGRÁFICA}

En Ciudad Real, el día 30 de octubre de 1877, nació nuestro personaje en el seno de una familia mitad extremeña mitad manchega. Su padre era abogado de profesión y gozaba de un cierto prestigio lo que, junto con alguna propiedad agrícola de mediana extensión, le confería una buena estabilidad económica.

A la edad de 16 años, tras acabar sus estudios de bachillerato en su ciudad natal, su padre, a pesar de que sus resultados escolares siempre fueron satisfactorios, decidió enviarlo interno a los agustinos de El Escorial como consecuencia de su relajada disciplina. Posteriormente se matricula en estudios de Derecho y Filosofía y Letras que le llevaron por distintas universidades españolas (Valladolid, Zaragoza y Madrid), obteniendo en esta última la licenciatura de Derecho (1898) y Filosofía y Letras (1900), continuando sus estudios de doctorado en Derecho que culminó en 1902 con la calificación de sobresaliente ${ }^{1}$. Posteriormente logró también, en 1915, el doctorado en Filosofía, defendiendo en este caso su tesis sobre La educación en inglaterra, que posteriormente publicaría, lo que ya revelaba sus inquietudes pedagógicas.

El inicio de estas inquietudes pedagógicas data de su conocimiento personal de D. Francisco Giner de los Ríos que se sitúa entre 1901 y $1902^{2}$, no habiendo estudiado nunca en la Institución Libre de Enseñan-

J. L. AbelLÁN: La crisis contemporánea (1875-1936). Madrid, Espasa Calpe, 1988, pág. 179

2 L. Palacios: José Castillejo. Última etapa de la Institución Libre de Enseñanza. Madrid, Narcea Ediciones, 1979, pág. 23. 
Educación y liberalismo institucionista durante la restauración canovista...

$\mathrm{za}^{3}$, en adelante ILE, de inspiración gineriana. No obstante, no hay completa certeza sobre la fecha exacta de ese primer contacto personal con Giner ya que hay versiones que lo sitúan en 1898 como alumno suyo. Nos quedamos, no obstante, con el primer dato ya que la esposa de Castillejo habla de que «justo cuando terminó sus estudios, Castillejo se puso en contacto con D. Francisco».

Castillejo interesó a Giner y entró así en el mundo de la ILE, participando de sus charlas interminables y de los paseos y excursiones a la Sierra de Guadarrama ${ }^{4}$. Sin duda, esto resultó decisivo para el resto de los días de nuestro personaje, quien absorbió la filosofía krausista enriquecida por Giner, según nos dice Luis Palacios, que se basa, con razón, en la deducción de un artículo del propio Castillejo en el Boletín de la ILE (el número 50, de 1926) enormemente revelador en este sentido. Orientó definitivamente su dedicación a la educación, dejando de lado cualquier aspiración a grandes puestos en política. Así, igualmente reorientó la ortodoxia católica recibida en los años de educación en los agustinos, rechazando «el dogma y todo aquello que no pudiera ser captado por la razón " ${ }^{5}$. Aunque su espíritu tolerante le hizo respetar cualquier postura.

Por entonces, 1903/1904, hizo su primer viaje, pensionado, al extranjero (Alemania). Este viaje, que había sufragado la Universidad de Oviedo hasta 1905, le sirvió a Castillejo para ir tomando contacto con instituciones sociales y administrativas de aquellos centros de enseñanza. "Quería averiguar, asimismo, cual era la labor científica realizada en ellas y cual su función pedagógica», nos comenta Ramón Carande. Todo ello sin descuidar en absoluto su formación. Aprovechó la ocasión de forma espléndida manteniendo contactos con profesores alemanes del prestigio de Kohler, Brunner, Gierke o Stammler 6 . A lo largo de su vida realizará gran cantidad de viajes al extranjero, todos ellos con la misma intención: recoger información y mejorar su formación académica para, al final, sacar rentabilidad en España en el mundo de la educación a todos los niveles.

En 1905 obtuvo la cátedra de Derecho Romano de la Universidad de Sevilla. En la capital andaluza pasó unos meses de intranquilidad y desasosiego. Su deseo permanente fue volver a Madrid, donde gozaría del

\footnotetext{
3 R. Carande: Un vástago tardío de la llustración: José Castillejo (1877-1945), en Galería de Amigos, Madrid, Alianza Tres, 1989, pág. 75.

4 VV.AA.: La Junta para Ampliación de Estudios, Revista Arbor n. ${ }^{\circ} 493$, de enero 1987, pág. 68.

5 L. Palacios: José Castillejo... op. cit., pág. 28.

- R. Carande: Un vástago... op. cit., pág. 77.
} 
contacto con el mundo de la cultura y su círculo de intelectuales más próximo. Lo repite en varias cartas a Giner. Por fin, en 1907, accede a la cátedra de la misma disciplina en la Universidad de Madrid 7 . Su método pedagógico era de corte socrático, muy parecido al de su maestro Giner: «recomendaba algunos manuales para algunos alumnos cuyo único interés era la obtención del título y trabajaba a lo largo del año con una minoría en largas discusiones y trabajos sobre los temas más diversos» ${ }^{8}$.

Estamos ya en una fecha clave para la vida y la obra de nuestro ilustre personaje, el año 1907. Previamente había sido nombrado agregado de relaciones con el extranjero del Ministerio de Instrucción Pública y se encargó de las pensiones que se concedían a estudiantes a propuesta de las universidades. Esto, junto con las estrechas relaciones mantenidas con Giner y con el conde de Romanones, facilitó enormemente el camino hacia lo que terminó siendo la JAE, encargándose él mismo de la confección de sus estatutos, así como del proyecto de Decreto para su creación. En enero de 1907, con treinta años de edad, se convierte en el alma mater de la Junta. Todos reconocen las extraordinarias dotes de organización, captación y persuasión, de este hombre que dedicó su vida a una transformación radical de España, hecha desde el silencio y la eficacia ${ }^{9}$. Durante casi tres décadas fue el Secretario de la JAE y la hizo viable a pesar de enormes problemas políticos y económicos, a pesar de las tremendas críticas recibidas desde posiciones conservadoras, y a pesar del mundo eclesiástico.

Los logros obtenidos por este gran hombre y la Junta para Ampliación de Estudios son, cuando menos, sorprendentes. Porque, además de conseguir enviar más de mil pensionados a las universidades extranjeras (principalmente europeas), con el consiguiente beneficio para la universidad y la cultura española, la Junta consiguió crear una serie de órganos directamente dependientes de ella misma con el fin de elevar el raquítico nivel intelectual y cultural de la España del momento. Algunos de estos organismos autónomos para la reforma educativa, como los llamó Castillejo ${ }^{10}$, alcanzaron enorme prestigio: la Residencia de Estudiantes (con Alberto Jiménez Fraud como director), la Residencia de Señoritas (dirigida por María Maeztu), el Centro de Estudios Históricos (con Menéndez Pidal al frente), el Instituto Nacional de Ciencias Físico-Naturales (con Ramón y

VV.AA.: La Junta para... op. cit., pág. 69.

lbidem, pág. 69.

J. L. AbELLÁN: La crisis... op. cit., pág. 180.

Ibidem, pág. 180. 
Cajal de Presidente, a su vez Presidente de la propia JAE), el Instituto Escuela, la Escuela de Párvulos de Simancas, etc.

En 1916 oposita a la cátedra de Sociología de la Universidad Central, lo que representó, a la postre, el único descalabro serio en su vida al ser postergado en beneficio de Severino Aznar. El tribunal estaba compuesto en su mayoría por vocales influidos por los miembros del profesorado de Sociología de los Seminarios de la Iglesia ${ }^{11}$. El asunto levantó una gran polémica como consecuencia de un artículo aparecido en la prensa días después, probablemente escrito por el propio Castillejo, y provocó la dimisión de algún profesor miembro del tribunal acusado de avenirse a arreglos poco decorosos. El mismo Castillejo presentó su dimisión a Ramón y Cajal quien, con buen criterio, no la aceptó. Tras este incidente no volvería nunca a mezclarse en oposiciones ${ }^{12}$, aunque luchó toda su vida por eliminar la arbitrariedad de las normas.

Hasta el año 1922 no consintió en cobrar su sueldo como Secretario de la Junta, y a partir de esta fecha lo hizo porque contrajo matrimonio con Irene Claremont, de nacionalidad inglesa ${ }^{13}$. Esta mujer, bastante más joven que él, era hija de una familia en cuya casa se solía hospedar Castillejo en sus múltiples viajes a Inglaterra. «Castillejo abandonó su pequeño cuarto de la Junta y fue a vivir a una casa que había diseñado y contribuido a construir él mismo, en un olivar cercano a los Altos del Hipódromo en la que tenía por vecinos a la familia Menéndez Pidal» 14.

Ya en 1927, en plena dictadura de Primo de Rivera, fue nombrado miembro del Comité de Cooperación Intelectual de la Liga de Naciones, gracias a su importante prestigio internacional. La comunicación le llegó a través del Ministerio de Instrucción y Castillejo aceptó dejando claro que lo hacía a título personal ya que tal nominación así lo indicaba, sin tener nada que ver con una representación estatal; de haber sido así, con toda seguridad no habría aceptado. Ese mismo año rechazó formar parte de una artificiosa Asamblea Nacional recién creada por Primo de Rivera, jugándose en el envite algo más que su prestigio personal. Salió bien, no obstante.

Con la llegada de la II República bajó la presión sobre el mundo intelectual, mejorando considerablemente la capacidad de acción de la JAE así como la expansión e intensidad de su labor. En 1934 Castillejo se hizo

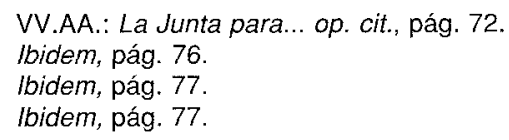


cargo de la dirección de la Fundación Nacional de Investigación acabada de crear. Dejó, como consecuencia, la Secretaría de la Junta en manos de sus ayudantes más experimentados ${ }^{15}$. En 1935 nuestro personaje rompió su escrupuloso silencio político, mantenido en aras de su proyecto pedagógico, e inició una colaboración semanal en el diario «El Sol», publicando una serie de artículos sobre los problemas que tenía planteados la República, donde demuestra ser un observador político agudo en extremo.

En1936, con la Guerra Civil, llega el exilio, no sin antes pasar por verdaderos apuros, con peligro claro e inminente de su vida, por haber permanecido fiel a sus principios. Fue detenido por unos milicianos, antiguos alumnos suyos, que le llevaron a las oficinas de la Junta para que les entregase las llaves. El Ministro de Educación, Domingo Barnés, también hombre institucionista, había sido avisado y pudo, tras delicadísimas negociaciones, embarcarlo hacia Inglaterra y evitar, así, su fusilamiento. Fueron diez días de verdadero sufrimiento y miedo.

Durante el exilio, que duró hasta el fin de sus días, trabajó en Ginebra como director de la Unión Internacional de Estudiantes, fue profesor en el Instituto de Educación de Londres, dio cursos en la Universidad de Columbia (USA), publicó artículos en Sudamérica así como algunos trabajos y «transmitió para España desde la BBC frecuentes comentarios sobre la situación política y cultural en España y el mundo» ${ }^{16}$.

Ramón Carande nos comenta en su artículo dedicado a Castillejo: «La última vez que le vi (y no puedo asegurar que él me viera) fue en una oficina úe la planta baja de la Dirección General de Seguridad, calle de Víctor Hugo, a fines de julio de 1936, detenidos ambos: él por unas denuncias y yo por otras. A los pocos días salió de España para siempre y durante su largo destierro no dejó de pensar en España (War of ideas in Spain. London, 1937). Murió en Londres el 30 de mayo de 1945."

\section{SU VERDADERA PASIÓN: LA EDUCACIÓN. LA JAE}

Dice Luis Palacios: «Castillejo se nos presenta como uno de los más conspicuos representantes de esos educadores y reformadores de la España contemporánea» ${ }^{17}$. En eifecto, como se ha venido comprobando a lo largo de su vida, la educación es una constante en su pensamiento, en

L. Palacios: José Castillejo... op. cit., pág. 68.

VV.AA.: La Junta para... op. cit., pág. 80.

17 L. PALACIOS: José Castillejo... op. cit., pág. 69. 
sus inquietudes. Para él, la educación es la tabla de salvación que necesita España para salir del subdesarrollo, de su abandono, de su intolerancia secular. Siguiendo a Giner y Cossío habla el ilustre manchego de que la verdadera aristocracia es el talento y, por consiguiente, la mayor fuerza de la sociedad moderna es la escuela ${ }^{18}$.

Ahora bien, para que la educación resulte todo lo eficaz que cabe desear debe ser completamente independiente del Estado y del Gobierno de turno, debe haber absoluta libertad en todo aquello que tenga que ver con el aspecto técnico de la misma. $Y$, por supuesto, en la enseñanza privada la independencia se extiende hasta el aspecto económico. Dice Castillejo, compartiendo una vez más el ideario gineriano, que «la educación es una función esencial, pero bajo ninguna circunstancia, un monopolio del Estado, representado por el Gobierno. Las escuelas privadas deben tener libertad para escoger sus métodos. Pueden hacer experimentos a pequeña escala y sin riesgo para la comunidad, pueden encarnar doctrinas que la mayoría rechace y, por consiguiente, más responsabilidad que los centros oficiales» ${ }^{19}$.

Lo cierto es que el libro de Castillejo Guerra de ideas en España, en su capítulo décimo titulado "Un paso hacia la reconstrucción" nos expone lo que él denomina el programa educativo de Giner y Cossío, el cual, al leerlo, nos parece su propio programa. Punto por punto parece haberlo absorbido osmóticamente, parece ya como algo propio, innato. En todos los puntos desarrollados en el capítulo está presente el pensamiento de Giner, ya que lo llevó a la práctica en toda su extensión. Y muy especialmente algunos de los aspectos que parecen haber sido como un guión de teatro para la Junta para Ampliación de Estudios que él, como nadie, encarnara. Es evidente, por lo tanto, así lo indican varios autores, la mano invisible de Francisco Giner en la constitución y funcionamiento de la JAE. En este sentido Castillejo parece haber sido la prolongación de la figura de Giner.

Más concretamente nos explica Isabel Gutiérrez, en un resumen clarificador, que "José Castillejo expone el programa educativo de Giner y de Cossío sintetizándolo en los siguientes principios: la mayor fuerza de la sociedad moderna es la escuela; la educación no deber ser un monopolio del Estado, ya que debe haber una enseñanza libre que escoja sus ideales y sus métodos, que pueda ser experimental y solo de este modo será fuente de progreso; en la enseñanza debe promoverse la innovación, la crea-

18 J. Castillejo: Guerra de ideas en España. Madrid, Revista de Occidente, 1976, pág. 97.

19 Ibidem, pág. 97. 
tividad y debe procurarse la reforma, pero bien planeada y bien meditada; para que la reforma sea eficaz debe tener muy en cuenta una adecuada e intensa preparación de profesorado, que debe conocer las experiencias positivas de otros países; España necesita muchas más escuelas elementales y acabar con el analfabetismo; para preparar al profesorado hay que enviarle a estudiar en el extranjero; deben ser respetadas las escuelas y universidades existentes, estimulándolas a que se reformen desde dentro, ya que una reforma no puede lograrse sólo porque la decrete una Ley ${ }^{20}$.

Según Giner, y por tanto según Castillejo, uno de los principales aspectos a tener en cuenta en la labor educativa es la función del maestro. Hasta tal punto es así que se supedita el número de escuelas, tan necesarias como escasas en la España de principios de siglo, al «número de maestros bien preparados. Sería un descrédito fatal el compensar la escasez nombrando malos maestros" 21 . Como dice Luis Palacios: "para Castillejo el maestro, en el más amplio sentido de la palabra, no debe ser un mero transmisor de cosas, sino un buscador de verdad, un buscador de ciencia». Solamente esto ya justificaría la existencia de una institución como la JAE que, mediante sus pensiones a estudiantes y profesores en el extranjero, subiría el nivel cultural en nuestra docencia al revertir los conocimientos adquiridos en «iniciar nuevos tipos de escuelas, colegios de magisterio o laboratorios..." 22 .

La mayoría de los principios detallados en el capítulo que estamos viendo se explican solos. Pero hay uno que me permito transcribir en toda su extensión porque seguramente hoy en día sería duramente atacado y sin embargo rebosa racionalidad por todas las partes, aunque, en justicia, también una cierta dosis de la deliciosa ingenuidad institucionista. Dice así: "la educación no debe ser obligatoria. Si las escuelas son lo suficientemente atractivas y útiles, la coacción es innecesaria porque los alumnos acudirán a ellas; y si son inútiles y aburridas, es una crueldad imponérsela a los niños. La obligación sólo las hace odiosas y repelentes". Por el contrario, el profesor Palacios nos dice claramente de Castillejo que «piensa que el carácter gratuito y obligatorio de la enseñanza se irá extendiendo a medida que evolucione la sociedad hasta que llegue a afectar

\footnotetext{
20 1. Gutierrez Zuloaga: El programa pedagógico de Giner y Cossio, en José Castillejo y la política europeísta para la reforma educativa española. Ciudad Real, Diputación de Ciudad Real Biblioteca de autores y temas manchegos, 1987, pág. 53.

21 J. Castiltejo: Guerra de ideas... op. cit, pág. 98.

22 Ibidem, pág. 99.
} 
Educación y liberalismo institucionista durante la restauración canovista...

también a la enseñanza universitaria» ${ }^{23}$. Se apoya Palacios en un párrafo extraído de Los ideales de la cultura española, y parece querer decir que Castillejo aboga por la enseñanza obligatoria, lo que, de ser así, se contradice de medio a medio con lo expuesto antes en este mismo punto.

Deben ser evitados, según Castillejo, la centralización, la uniformidad, la rutina, la rigidez, entre otros vicios. Como dice Palacios, insiste una y otra vez en el hecho diferencial que debe caracterizar a cada escuela. La escuela debe ser resultante del mundo social. Así, por ejemplo, la construcción de un centro escolar, por lógica, ni puede ni debe ser igual en un lugar de temperaturas frías en extremo y con pocas horas de luz que en un lugar donde la bonanza de su climatología permita edificaciones con grandes espacios abiertos (uno de los anhelos ginerianos es la escuela al aire libre). La centralización trae como compañeras de viaje la uniformidad, la rigidez y la rutina. No le faltaba razón a nuestro personaje. Muchos de nosotros hemos podido comprobar vicios como los apuntados durante décadas. «No hay nada más pernicioso que una ley que regule la instrucción pública trazando un esquema general, sintético y completo para todo el país» ${ }^{24}$.

Es esencial para José Castillejo, ante todo, formar hombres, porque las cosas no son posibles «haciendo abstracción del hombre». Según Carmela Gamero, Castillejo aspira a una reforma de la sociedad a partir de la transformación de la educación y concretamente del hombre. Y, sigue diciendo, que considerá que la educación debe tender a hacer hombres y por tanto ha de ser obra de tolerancia y neutralidad, lejos de toda pasión política y religiosa ${ }^{25}$. Había dicho nuestro personaje en una conferencia pronunciada en Bilbao en 1911: «no es problema de hacer escuelas, sino maestros, ni hacer universidades, sino científicos, no fábricas, sino industriales, ni credos, sino creyentes, ni leyes nuevas, sino hombres nuevos».

¿Qué decir de las reformas?. En su Guerra de ideas dice el ilustre manchego: «La reforma debe confiarse a un cuerpo pequeño de no más de siete a nueve personas, competentes, entusiastas, prudentes, totalmente independientes y que reprezenten las diferentes líneas de pensamiento del país. Debe estar completamente fuera de la influencia política y sectaria y debe abstenerse de intentar innovaciones que puedan llevar a una disputa política o religiosa» ${ }^{26}$. Resulta inevitable que nuestro pensa-

23 L. Palacios: José Castillejo... op. cit., pág. 78.

24 J. Castillejo: Guerra de ideas... op. cit., pág. 99.

25 C. Gamero: Un modelo europeo de renovación pedagógica: José Castillejo. Madrid, CSICInstituto de Estudios Manchegos, 1988, pág. 64.

26 J. CASTILlEJo: Guerra de ideas... op. cit., pág. 99. 
miento nos lleve hasta la Junta para Ampliación de Estudios, donde podemos afirmar que se cumple este párrafo punto por punto. Abundando en el tema, más adelante, insiste Castillejo y dice que «para intentar las reformas era necesario evitar varios enemigos, la opinión conservadora que se asustaba fácilmente; asociaciones profesionales de maestros, muy celosas ante los intrusos y algo escépticas ante las innovaciones; la Iglesia, que no toleraba ninguna escuela fuera de su control; los políticos, que quedaban desilusionados si los cambios no se llevaban a cabo a gran escala y con reglamentación profusa; la burocracia vinculada a los textos legales uniformes; e incluso los padres acostumbrados a ver la acción oficial emparejada con la destrucción y el despilfarro ${ }^{27}$. Seguimos recordando a la Junta, donde tuvo serios problemas con los políticos conservadores de turno; con la Iglesia, dominadora absoluta en materia de enseñanza en aquellos tiempos; en cuestiones económicas huía del despilfarro como de la peste hasta tal punto que llegaba a ser irritante y rayaba la tacañería. Estaba justificado, no obstante, dada la escasez del presupuesto y su interés en enviar al extranjero tanta gente como le fuera posible.

Como el mismo Castillejo decía, «la vocación debe cultivarse por encima de cualquier otro interés o ambición» 28 . Tan institucionista frase la trasladó, con todas sus consecuencias, a su propia vida. Ya hemos dicho que renunció a cobrar sueldo alguno durante años, accediendo a ello solamente cuando contrajo matrimonio; renunció igualmente a cualquier cargo político al que, con seguridad, hubiera podido acceder. Como fruto de esa vocación suya y de su abnegada dedicación nació y se desarrolló la JAE. Cierto es que tuvo colaboraciones importantes, pero él fue el verdadero artífice de la Junta y de sus importantes éxitos. Honestidad, tolerancia, disciplina, son algunas de las grandes virtudes que adornaban su persona y que imprimió a la Junta, de la que, además, se descolgaban otras instituciones de carácter educativo que alcanzaron también un gran prestigio. Tal fue el caso de la Residencia de Estudiantes (con su extensión para señoritas), el Instituto Escuela o la Escuela de párvulos de Simancas ya comentadas.

La JAE, con su clara inspiración gineriana, fue llevada a la práctica por este competente hombre. Como hemos dicho tuvo colaboraciones, claro está, de gentes de la importancia y el nivel de Santiago Ramón y Cajal, Gumersindo de Azcárate, Álvarez Buylla, Ignacio Bolívar, Menéndez y Pelayo, Joaquín Sorolla, etc. Así hasta un total de 21 miembros 
«de todos los matices de la opinión pública: católicos, republicanos, ateos, carlistas, etc. ${ }^{29}$.

Encontró también Castillejo apoyo en algún político liberal, y en especial hay que hacer una mención a Romanones que fue su principal valedor en el campo político y quien más confió en él. Todo lo contrario en los conservadores. Así, en 1907, el día 11 de enero se crea la Junta para Ampliación de Estudios «bajo el gobierno liberal de Vega Armijo, con Amalio Gimeno como ministro de Instrucción Pública ${ }^{30}$. Pocos días después, el 25 de enero accede a la Presidencia del Gobierno D. Antonio Maura que entrega la cartera de Instrucción Pública a Rodríguez San Pedro (el ministro pisapapeles, en palabras del propio Maura). Ambos, pero este último de forma más directa, se encargaron de poner en el congelador la Junta, como nos dice el profesor Cacho Viu. La caída en 1910 de Maura representa el inicio de un periodo de expansión (1910/1913) bajo los gobiernos liberales de Moret y Canalejas. Durante la I Guerra Mundial se paralizaron las pensiones en Europa, iniciando un mayor acercamiento hacia los Estados Unidos de América.

El final de la Gran Guerra representa el relanzamiento de las pensiones $y$, hasta 1923, hubo unos cuatro años de calma y de desenvolvimiento normal de sus actividades. En 1923, nuevo cambio de aires. Primo de Rivera protagoniza su golpe militar y empieza una época de penurias y de serias dudas incluso para la seguridad física de sus principales hombres (recordemos el episodio en que Primo de Rivera insta a Castillejo a formar parte de su proyecto de Asamblea Nacional que éste rechazó con riesgo de su vida). En 1930, con Berenguer en el gobierno, se recuperó parte de la autonomía perdida. Y ya con la II República volvieron los tiempos de relativa bonanza para la Junta: «era, al fin y al cabo, la República de los intelectuales, muchos de ellos (de los Ríos, Azaña, Besteiro, Zulueta,...) entroncados, directa 0 indirectamente, con la institución Libre de Enseñanza» ${ }^{31}$. Pese a todo no estuvo exenta de serios problemas, si bien eran de otra índole: alguna de las decisiones políticas de la República y especialmente su actitud con las escuelas de las órdenes religiosas y, por lo tanto, con la libertad de enseñanza. Dice Castillejo al respecto: «En educación secundaria el esfuerzo de la República se ha dirigido a sustituir las suprimidas escuelas de las ordenes religiosas por escuelas estatales.

29 L. Palacios: José Castillejo... op. cit., pág. 92.

30 J. M. SÁnchez Ron: La Junta para Ampliación de Estudios e Investigaciones Científicas 80 años después. Madrid, Consejo Superior de Investigaciones Científicas, 1988, Vol. I, pág. 5.

31 lbidem, pág. 17. 
Los edificios y el equipo fueron confiscados y se nombraron maestros rápidamente. Era parte de la mal concebida campaña contra la situación ilegal de la Iglesia. Muchos de los niños fueron retirados por sus familias. Fue un golpe a la libertad de enseñanza» ${ }^{32}$.

La JAE muere al poco de estallar la Guerra Civil, como una víctima más de tantas como se causaron durante y después de ésta, aunque sus consecuencias fueron, si cabe, más lamentables (vidas humanas aparte) por el efecto destructivo en materia científica y cultural que representó para España a partir de aquellos momentos. Y no es tan sólo que el llamado bando nacional decretara su final en mayo de 1938. «Renovada la Junta de la Asociación de Catedráticos de Instituto el 18/8/1936, a la que sólo podían pertenecer miembros de partidos integrados en el Frente Popular, deciden incautarse de los edificios de la JAE, que era contemplada con recelo por un sector del profesorado de izquierdas (iquién lo hubiera imaginado en tiempos de Rodríguez San Pedro!), e iniciar la depuración de su personal» ${ }^{33}$. Muchos de ellos habían pertenecido a la Institución y/o a la Junta.

Las palabras de Castillejo resultaron ser premonitorias: «el advenimiento de la República atrajo a la política a muchos de los líderes intelectuales preparados por la Junta. No han mostrado instinto político o sentido de la responsabilidad social, cualidades que no se consiguen en los laboratorios, y su deserción de éstas ha roto el marco científico todavía débil del país. Las persecuciones revolucionarias o reaccionarias al final los echarán de España y quizá América Hispana recogerá parte de la cosecha cultivada en la Madre Patria ${ }^{34}$.

Pero además de las vicisitudes históricas, políticas y económicas por las que tuvo que pasar la JAE hasta su disolución en 1937 en la zona nacional, (en la zona republicana mantuvo una cierta actividad testimonial concretamente en Valencia, en la Casa de la Cultura), además, digo, la Junta es un gran proyecto que intenta dar la vuelta a la maltrecha cultura y al sistema educativo en España. Lo que Castillejo denomina un Directorio apolítico permanente es lo que luchó por conseguir la JAE durante toda su existencia y su Secretario en particular. Como dice nuestro personaje y como amplía después el profesor Palacios, por su apoliticidad fue difícilmente digerible por los políticos españoles que deseaban intervenir en su funcionamiento. Recordemos aquí que la independencia era uno de los

J. Castillejo: Guerra de ideas... op. cit., pág. 136.

J. M. SÁnchez Ron: La Junta para Ampliación... op. cit., pág. 53.

J. Castillejo: Guerra de ideas... op. cit, pág. 136. 
anhelos ginerianos. Pero precisamente este aspecto de la Junta fue lo que, añadido a la extraordinaria habilidad de Castillejo, su diplomacia, su brillante oratoria, su capacidad para convencer, permitió su existencia y el importante éxito obtenido por la misma en épocas tan poco propicias al desarrollo cultural. Ese increíble juego de equilibrio (con representantes de todas las tendencias de pensamiento en su seno) que era la Junta para Ampliación de Estudios, y que conduciría con maestría D. José Castillejo, fue la clave de su éxito.

Este Directorio apolítico, la JAE, pretende ir adelante apoyándose en dos puntos fundamentales:

«a) provocar una corriente de comunicación científica y pedagógica en el extranjero.

b) agrupar en los núcleos de trabajo intenso y desinteresado los elementos disponibles del país» ${ }^{35}$.

La Junta pretende pues, impulsar, organizar e iniciar «una renovación intensa y rápida de nuestra educación superior y nuestros investigadores científicos" ${ }^{36}$. Se utiliza para ello el ya antiguo sistema de becas o pensiones, de ahí el nombre otorgado a la JAE vulgarmente de «Junta de pensiones». Pero, como dice Sánchez Ron, no todo se limita a pensiones. El Decreto Fundacional aclara «qué hacer con los pensionados a su regreso a España, que era donde realmente habría de producirse el beneficio de tan considerable inversión» ${ }^{37}$. Así, la JAE tenía a su cargo:

«1. el servicio de ampliación de estudios dentro y fuera de España.

2. las Delegaciones en congresos Científicos.

$3 .^{\circ}$ el servicio de información extranjera y relaciones internacionales en materia de enseñanza.

4. el fomento de los trabajos de investigación científica.

5. la protección de las instituciones educativas en la enseñanza secundaria y superior» ${ }^{38}$.

Por lo tanto y más concretamente: a) se concedían becas para el extranjero, a las que podía acceder cualquier español preparado y con in-

\footnotetext{
C. Gamero: Un modelo europeo... op. cit., pág. 34.

Ibidem, pág. 34.

J. M. Sánchez Ron: La Junta para Ampliación... op. cit., págs. 7-8.

lbidem, pág. 8 (del Real Decreto fundacional).
} 
terés, pudiendo elegir el tema con entera libertad; b) se crearon Instituciones de investigación que permitían facilidades para dedicarse a la investigación -entre otros centros se crearon el Instituto Nacional de Ciencias Físico Naturales, el Centro de Estudios Históricos o la Escuela Española de Roma-, elevar el nivel en España, publicar sus contribuciones, instruir al futuro cuerpo docente de la universidad; c) se fundaron Escuelas y Colegios que pretendían cubrir todo el periodo escolar, con dos secciones: el Instituto Escuela, que cubría hasta la edad de 17 años - en este punto recibe Castillejo el influjo de Cossío y la influencia de Luis Vives, quien siglos antes había abogado por una escuela que acogiera alumnos de siete a veinticinco años, ligando la primera enseñanza a la secundaria y a la superior- y la Residencia de Estudiantes que complementaba a la Universidad y suplía ciertas carencias de esta; d) cuidaba de la cultura española en el extranjero: atendía estudiantes extranjeros en España, enviaba conferenciantes y profesores al extranjero, etc.; e) apoyó la creación del Institut d'Estudis Catalans para investigar sobre asuntos exclusivamente catalanes ${ }^{39}$.

Todas las acciones de la Junta estaban financiadas por el Estado, sin menoscabo de algunas donaciones, sobre todo de españoles residentes en Sudamérica, así como de sus publicaciones y de las cuotas. Y todas estas acciones estaban controladas minuciosa y eficazmente por Castillejo. Dice Jiménez Fraud que «Castillejo trabajaba incesantemente en su oficina, visitaba los centros de la Junta, frecuentaba diariamente el Ministerio para contrarrestar los continuos entorpecimientos que la rutina administrativa, la incomprensión del intento, o la mala voluntad de sus enemigos creaba». Pero como nos comenta Carmela Gamero: «siguiendo el ejemplo de su admirado maestro Giner, intentó pasar desapercibido, huía de todo protagonismo. Dice su esposa que su poder residía en su capacidad de permanecer invisible».

No obstante todo lo anterior, y siguiendo a Vicente Cacho Viu, hablando de España, "la carencia de un verdadero partido liberal, mientras se mantuvo el régimen parlamentario, limitó los avances de la Junta a unos cuantos golpes de mano afortunados que se tradujeron en la creación de unos centros, pero nada se hizo para utilizar de manera genérica la experiencia en ellos acumulada». Y sigue diciendo: «la Junta, después de algunas escaramuzas, sería al fin respetada, pero nada hizo más patente su condición de jaula de oro, en la que se confinaba a la minoría liberal, que

39 J. Castilleso: Guerra de ideas... op. cit., págs. 102 y ss. 
la ocurrencia de competir con ella, creando con la Ciudad Universitaria de Madrid otro escaparate mucho más vistoso, aquejado además del gigantismo con que los Estados débiles tienden a enmascarar su ineficiencia operativa». $Y$, concluyendo, dice: "los frutos, o si se quiere, la responsabilidad de la Junta, no se sitúan en el plano político, al que nunca tuvieron acceso sus ideas de cambio, sino en el social: Su balance completo, el día que se haga, será el balance de lo que hayan aportado a la modernización española los casi dos millares de alumnos del Instituto Escuela y otros tantos becarios fuera de España, y los residentes de Fortuny y de Pinar. La polarización fratricida del país entre quienes o no eran burgueses o no eran liberales, dejó sin espacio a la Junta y a la mayoría de sus gentes» ${ }^{40}$.

\section{SU PENSAMIENTO LIBERAL}

«El hombre es dueño de su silencio y esclavo de sus palabras». Esta célebre cita podría resumir una parte importante de la vida de José Castillejo, que tendría inicio al mismo tiempo que su obra, la Junta para Ampliación de Estudios, en 1907, y final con su propia muerte en Londres, en 1945.

Dividiendo este periodo en dos partes, la primera, la silenciosa, dura hasta 1935, aunque alyo antes se producen los primeros acercamientos a la prensa escrita ya que «en 1932 Castillejo empieza a publicar artículos en El Sol, y con bastante regularidad desde el otoño de 1934 hasta estallar la guerra civil en julio de $1936{ }^{41}$. En esta primera fase, aunque no exenta de serios problemas, Castillejo es dueño de sí mismo, no habla de política cuando se le pregunta, él sólo entiende de lo suyo, la enseñanza («los intelectuales no tienen intuición política» dirá, como casi todos los intelectuales del momento). La segunda parte, desde 1935, representa su esclavitud respecto de sus palabras, y lo estuvo purgando hasta el fin de sus días. Fue una «quema de naves» involuntaria ya que él nunca pensó que esto le podría llevar al destierro de su España querida. Rompe, pues, su silencio político que tan prudentemente había preservado, quizá sintiéndose arropado con los políticos que dominaban la República, muchos de ellos procedentes o simpatizantes de la Institución Libre de Enseñanza

40 V. CACHO: La Junta para Ampliación de Estudios, entre la Institución Libre de Enseñanza y la Generación de 1914 en J. M. SÁnchez Ron: La Junta para Ampliación... op. cit., Vol. II págs. 25-26.

41 D. Castillejo: Fatalidad y Porvenir (1913-1937). Epistolario de José Castillejo Vol III. Madrid, Editorial Castalia, 1999, pág. 682. 
o de la JAE. Grave error. De ese escaso año y medio de críticas abiertas a la República y sus métodos, unido a sus acciones llevadas a cabo en aras de una libertad que pocos entendieron y muchos menos compartieron, se derivaron las consecuencias que estamos comentando, llegando a poner en peligro su vida en los primeros compases de la guerra civil.

Es de destacar, y de ahí el título de este capítulo, su liberalismo de profunda e inteligente convicción. Repasando sus artículos en prensa 0 sus charlas radiofónicas desde Londres observamos la reiteración de palabras como libertad, democracia liberal o libertad de enseñanza (libre de políticas o credos intolerantes). Y, como no podía ser menos, el ejemplo a seguir sería la liberal Inglaterra de la época. Parece mantener una indesmayable lucha intelectual contra la intolerancia religiosa y contra las dictaduras (del signo que sean). Su esperanza es siempre la juventud en la que confía como verdadera tabla de salvación siempre y cuando se le dé una educación adecuada, sin prejuicios, exenta de imposiciones políticas o religiosas; aunque lo primero y más importante sería su educación humana, su formación como hombres.

El punto de inflexión en su actitud silenciosa fue, como hemos dicho, el año 1935. José Castillejo va a romper su silencio político, mantenido durante toda su vida. El dato es importante porque su destino posterior, y en particular la enemiga desatada contra él por sectores del Frente Popular, se han achacado a ello. Desde mediados de ese año se publica un artículo semanal en el diario El Sol, comentario político de Castillejo al hilo de los acontecimientos del día ${ }^{42}$. Resulta cuando menos chocante que, años más tarde, a propósito de las charlas desde la BBC, el Ministerio de Relaciones Exteriores de España se quejara ante la Embajada británica de que «el micrófono de la BBC estuviera en manos de rojos tan conocidos como Madariaga (que jamás había hablado desde la BBC para España), Castillejo y Torres" ${ }^{43}$. Convengamos en lo difícil que resulta ser libre, y en aquellos momentos lo era mucho más.

A menudo podemos leer excelentes críticas tanto sobre los artículos como sobre las charlas de nuestro personaje. Calificativos como brillante y agudo observador, altura de pensamiento, etc., jalonan cualquier texto que podamos leer a propósito de $\mathrm{D}$. José Castillejo. $Y$ esto indistintamente de que se trate de su época en la JAE o de sus acertadas críticas políticas.

42 VV.AA.: La Junta para Ampliación de Estudios, (2. ${ }^{a}$ parte), Revista Arbor $n .^{\circ} 499-500$, de julio-agosto, 1987, pág. 109.

43 R. Martinez Nadal: Don José Castillejo en el exilio, las emisiones de la BBC, en José Castillejo y la política europeísta..., op. cit., pág. 244. 
Educación y liberalismo institucionista durante la restauración canovista...

Una curiosidad que cita Martínez Nadal a propósito de sus charlas en la BBC nos da idea de la calidad de sus comentarios y su reconocimiento por los oyentes: "y los oyentes españoles preguntaban extrañados: pero, ¿dónde estaba este profesor que nunca oímos hablar de él? » 44.

La brillantez de sus críticas no estaba exenta de dureza hacia el gobierno de la II República, especialmente por estar compuesto en gran medida por intelectuales, pero también por los resultados de la política que estos aplicaron. Como hemos apuntado antes, solía decir que los intelectuales carecían de instinto político. En esto estaba en la misma línea de opinión que la mayoría de los intelectuales del momento, especialmente los que componían la orteguiana Agrupación al Servicio de la República (no tanto los azañistas de Acción Republicana que, junto con los socialistas componían el grueso del gobierno del primer bienio republicano). Dice Anselmo Romero: «no le inspiran mucha confianza los políticos ni lo hombres de ciencia metidos a políticos" ${ }^{45}$. El nivel intelectual de mayor calado de la época estaba en el entorno de Ortega y no en el de Azaña. Sin duda nuestro personaje sintonizaba mejor con el primer grupo.

En sus artículos sobre la República española hace un repaso de los aspectos más destacados como la propia Constitución, el problema religioso, los partidos políticos, la intolerancia, la educación, etc., y desde luego que reciben en muchos casos críticas durísimas. Así, por ejemplo, para Castillejo la Constitución de 1931 fue elaborada con prisas. Hubiera sido preferible un periodo de moderación y reformas que consolidara la conquista republicana. Decía que era más fácil «proclamar una república que instaurarla, y teníamos quizá razón la docena de españoles que soñamos con un quinquenio de ensayos, sin Constitución ni armatoste monárquico conocido; un quinquenio de liquidación, de tregua... puede que al finalizar esa etapa hubiéramos caído en la cuenta de que podíamos pasar sin ley fundamental; pero si la fraguábamos hubiera recogido formas vitales genuinas y no frases y recortes ${ }^{46}$. El resultado fue una Constitución ambigua que servía "desde la dictadura oligárquica al comunismo". Y entre sus características la que más destaca para nuestro autor, por sorprendente, es su orientación conservadora: «ni un solo intento - dirá Castillejo— de transformar en su esencia la armazón social y

44 R. MARTínez NADAl: El hombre y su quehacer en la Voz de Londres (1940-1945). Madrid, Editorial Casariego, 1998, pág. 41.

45 A. Romero: España vista por Castillejo, en José Castillejo y la política europeísta..., op. cit., pág. 41.

46 J. Castillejo: «Los problemas de la República: ¿Necesita un presidente?», El Sol, 19.04.1936. 
política, la economía, la enseñanza, la sanidad, la administración central o la vida municipal».

La cuestión religiosa es una de las constantes que aparecen en los comentarios políticos de José Castillejo, y le concede una importancia vital de cara a la convivencia de los países y los puebios, de hecho en su charla Unidad nacional sin lágrimas (23-XI-44) establece tres grandes lazos para la formación de las nacionalidades, el Derecho, la Religión y la Economía. Así, en otra de sus charlas, Mensaje del año 1944 (31-XI-44), dice: «Tampoco habrá paz política sin paz religiosa. Los países que no la permiten llevan latente la más venenosa de las guerras civiles. Contestar a una propaganda comunista con una cruzada católica es echar leña al fuego... Solo cuando una religión cesa de inspirar fe se alía con la fuerza» ${ }^{4}$.

En España se le tenía un gran temor al poder de la lglesia y se le quiso despojar de la enorme fuerza política que tradicionalmente había tenido «aplicando el sistema tradicional de persecuciones con pena de confiscación». Esta postura de los políticos republicanos y su plasmación práctica más patente que fue el cierre de los colegios de los Jesuitas y otras órdenes religiosas, no podía traer más que una mayor radicalización. Para interceder en favor de la libertad de enseñanza, visitó a Fernando de los Ríos, a la sazón Ministro de Instrucción Pública, y le preguntó como último argumento: «pero, Fernando, si cerráis los colegios religiosos, ¿de donde saldrán los futuros ateos?» ${ }^{48}$.

Hay otro aspecto que está muy presente en su pensamiento político. Se trata de las dictaduras. Reciben, como no podría ser de otra forma en un librepensador como Castillejo, duras críticas poniendo de relieve, negro sobre blanco, las enormes carencias y los grandes defectos que les son inherentes. Tras años de observación atenta, nuestro personaje concluye que «lejos de significar unidad, delatan el fraccionamiento interno», la persecución del oponente ideológico, la eliminación de los partidos, la prohibición de libros o de religiones distintas de la oficial «se hace porque no hay unidad nacional, sino un país enfermo y descoyuntado cuya suerte pende de un hilo. Las gentes se preguntan aterradas; ¿qué va a pasar aquí a la muerte o a la caída del dictador? Esa pregunta revela que nadie cree en la unidad de que él se ufana» ${ }^{49}$. $Y$ ello porque los que soportan una dictadura temen la llegada de una democracia jacobina. Temen el efecto péndulo.

\footnotetext{
47 R. Martínez Nadal: El hombre y su quehacer... op. cit., pág. 160.

48 lbidem, pág. 37.

49 Ibidem, pág. 152.
} 
Educación y liberalismo institucionista durante la restauración canovista...

Los gobiernos totalitarios han dado a las persecuciones rigidez cruel y casi mecánica. «Solo en Europa - dice Castillejo-, unos 20 millones de seres humanos han sido arrancados de sus hogares. ¿Qué mayor prueba de la incapacidad política de las dictaduras? ${ }^{50}$. No le falta razón a nuestro D. José. La incapacidad de las dictaduras se manifiesta a cada paso. En su charla Democracias absolutas y democracias liberales nos da otra muestra de ello. Dice así: "Oír al pueblo no es democracia, es orientación, semejante a la brújula que no nos impone una dirección pero nos permite tomarla. Gobernantes sin oídos son navegantes sin brújula. ¿Y como pueden oír sin que haya libertad de pensamiento y de expresión? ¿Quién se atreve a criticar bajo la amenaza de ser fusilado o de ir a la cárcel como traidor?» ${ }^{51}$. En efecto, si nos preguntamos cual es el principal activo con que cuenta un Estado seguramente convendríamos en que son sus gentes. $\mathrm{Si}$ coartamos o simplemente impedimos sus diferentes manifestaciones nunca podremos sacar provecho de todas aquellas ideas que son capaces de desarrollar. Volveríamos a decir, con Castillejo, ¿qué mayor prueba de incapacidad política de las dictaduras? Y, por finalizar con este tema, nos dice el profesor manchego, y es verdad, que las democracias vencen una vez más a las dictaduras. Esto es así porque las dictaduras sólo enseñan a obedecer a los que mandan, mientras que en las democracias, especialmente la inglesa, la educación es libertad e iniciativa personales que se terminan demostrando en todas las facetas de la vida.

Libertad, democracia, tolerancia, son conceptos que Castillejo no se cansa de repetir. La tradición liberal inglesa es el secreto del éxito de aquel país. Esta tradición empieza en las escuelas. Así, mientras en Alemania «la vida es la ejecución de un plan ordenado por la autoridad ... para el inglés la autoridad es como una medicina que sólo se aplica para remediar un dolor o un defecto vital» ${ }^{52}$. Esto podría explicar porqué en Alemania se dio una dictadura nacionalsocialista mientras en Inglaterra es poco menos que impensable. El liberalismo viene a ser el antídoto contra las dictaduras. $Y$ esto se consigue sencillamente mediante la plena libertad de enseñanza. No había colegios ni universidades inglesas de titularidad pública, con la única excepción de las escuelas regidas por los municipios. Las demás dependían de fundaciones, congregaciones religiosas o sociedades privadas. Mientras, en España, y en muchas partes del continente, se expulsaban a las órdenes religiosas que habian tenido en sus manos durante siglos la educación de sus gentes, con el inmenso daño

$50 \quad$ lbidem, pág. 172.

51 lbidem, pág. 53.

52 lbidem, pág. 106. 
que una medida de tal magnitud suponía para el país al no tener preparada una sustitución satisfactoria. $Y$ ello sin contar con el daño que a la tolerancia y a la convivencia hacía semejante medida. La cuestión no es educar. La cuestión es «educar para la democracia», no educar para los ideales de quien ocupe el poder en cada momento. Siempre estaremos empezando y siempre habrá una parte de la sociedad que se considerará agraviada y privada de sus derechos. El concepto clave es la tolerancia. $Y$ en este sentido, aun en los países más adelantados del continente se «cuelgan en los muros textos de leyes, decretos ministeriales, reglamentos escolares, y órdenes del Director. El niño comienza aprendiendo las cosas prohibidas» ${ }^{53}$. Por el contrario «el inglés pide a la escuela justamente lo que no puede dar el libro: un ambiente educador, ..., la tolerancia, la asociación libre, .... el juego limpio, ...» ${ }^{54}$.

Finalmente, la democracia, de acuerdo con Castillejo, «con aciertos y desaciertos, es la paz política». Y es que Castillejo es, en palabras de Luis Palacios, un convencido demócrata, pero no como un sistema de opresión de las mayorías sobre las minorías como ocurría en la España de la II República. Podemos concluir que Castillejo pensara realmente que en la España republicana había democracia; pero el fracaso venía de la carencia importante de liberalismo real. «Lincoln Ilamaba democracia al gobierno del pueblo. Churchill la define como derecho a derribar al Gobierno» ${ }^{55}$. Entre el concepto clásico, helénico, que manifiesta el norteamericano, y el avanzado y liberal del inglés puede haber la misma diferencia que entre la democracia española de la II República y la que realmente deseaba nuestro personaje.

\section{LA MÉDULA DE LA POLITICA ESPAÑOLA}

Éste es el título de un documento que merece comentario aparte por tratarse del último testimonio escrito que dejó José Castillejo justo antes de su muerte, y por representar, según Martínez Nadal, el testamento político del personaje. En él, el autor realiza un corte longitudinal a nuestra historia política abarcando el periodo durante el que transcurrió su propia vida. Así, saca a relucir cuales eran, a su juicio, los asuntos que tenían que solucionar los españoles para el éxito en su futuro.

53 Ibidem, pág. 107.

54 Ibidem, pág. 107.

55 Ibidem, pág. 160. 
El triunfo definitivo de los liberales sobre los absolutistas (carlistas) en 1875 se ve coronado con una labor que Castillejo anota en el haber de los dos personajes políticos más destacados del momento, Cánovas y Sagasta, confiriendo al último una importancia mayor de lo que es habitual en las publicaciones que tratan aquel periodo de fin del siglo XIX. El profesor manchego ensalza el trabajo, aunque sin entusiasmo, de la Restauración: «su obra legislativa -la de los dos líderes- dio a España medio siglo de restablecimiento y prosperidad». Destacaba Castillejo, entre los problemas y resistencias que encontraron los dos estadistas, el sempiterno problema español, la religión, representado por el Concordato de 1851; un ejercito "acostumbrado a ser árbitro del país» y además dividido; el partido republicano siempre muy activo; el movimiento autonomista catalán que por aquellas fechas empezaba a tener cierto peso; el partido socialista, que apoyaba a los liberales, y a la mínima oportunidad les montaba «huelgas revolucionarias; que era tanto como llamar a los conservadores»; Bakunin y el anarquismo, siempre listos para lanzar su arma preferida, la violencia, contra el gobierno del turno, a menudo débil.

Habla Don José del surgimiento, en España, del krausismo en 1868 y de sus excelencias, de las simpatías que despertaba el krausismo español y su hija, la Institución Libre de Enseñanza, fundada a raíz de los problemas que sufrieron sus profesores como consecuencia del deplorable Ministro Orovio (persecuciones, destierros, privación de cátedras), de los logros materializados en reformas políticas (Senado de 1876) o sociales (Instituto de Reformas Sociales) o educativos (Junta para Ampliación de Estudios y envío de pensionados al extranjero, Residencia de Estudiantes). Todos estos logros revisten especial relevancia para la cultura española que alcanzó unos hitos insospechados y que se codeaba con lo más granado de la cultura europea del momento. $Y$ desde luego no gracias a los presupuestos que destinaban los gobiernos a este capítulo.

Hay cuatro personajes clave para Castillejo, a los que ensalza, que «simbolizaban la unidad nacional», aspecto éste de gran importancia para él. Estos eran Pablo Iglesias, Marcelino Menéndez Pelayo, Santiago Ramón y Cajal y Francisco Giner de los Rios. Viendo los personajes en cuestión y conociendo su procedencia y afinidades políticas comprobamos que el manchego era hombre de pocos prejuicios y en absoluto sectario.

La II República acabó, en 1931, con «toda la obra conciliadora de medio siglo". Castillejo critica con acritud las formas precipitadas y la 
inexperiencia política de los intelectuales burgueses que la hicieron posible. No obstante no les regatea el halago por el esfuerzo realizado en aras de la educación popular. Critica igualmente, y no es para menos, la Ley de Defensa de la República que permitía "clasificar a los ciudadanos en buenos o malos republicanos". Califica de anticonstitucionales las leyes contra las Congregaciones religiosas, y no parece que nuestro personaje, ni su maestro, Giner de los Ríos, en quien se apoya, sean sospechosos de clericales.

Para José Castillejo la fractura de la sociedad española era palpable, y dice: "Quedaron frente a frente la democracia socialista antieclesiástica y burguesa y la coalición de católicos y capitalistas. El ejército y la policía fueron partidos en dos sectores, uno viejo y el otro republicano. Todo estaba preparado para una guerra civil. Las masas obreras, divididas entre sí y divorciadas de la burguesía acogieron con entusiasmo la República pero no se sometieron a ella». La Iglesia, el ejército y los fascistas ganaron la guerra con la ayuda alemana e italiana. Leyendo entre líneas se aprecia un cierto resentimiento del autor hacia las potencias democráticas que no intervinieron en apoyo de la República.

Ya hacia el final del documento se adivina en nuestro personaje una cierta ingenuidad, tal vez guiado por sus deseos, al explicar lo que podrían haber hecho la Iglesia vencedora (nada menos que permitir la plena libertad religiosa), el ejército y el gobierno. Se hizo todo lo contrario de lo que él hubiera querido, retrocediendo incluso a actuaciones que ni en el siglo XVII se practicaban (fusilamientos, depuraciones y campos de concentración, entre otras).

Castillejo finaliza diciéndonos los signos de desprestigio del régimen y los temores de sus sectores más significados en volver a una nueva guerra civil. Hay que evitarla. Pero ¿cómo?, se pregunta Don José. Y se responde: «hay que dar un corte. Una declaración hecha por jefes de los varios partidos anulando todas las condenas y garantizando que nadie pueda ser procesado por actos pasados establecería una ley penal para el nuevo régimen, ley aplicable a todos y aplicada por tribunales independientes». Es una solución transaccionista que mucha gente ha rechazado, pero el tiempo le está dando la razón a nuestro personaje. Queda patente, a lo largo del texto, que José Castillejo gustaba de soluciones pactadas, poco amigo de revoluciones y sobresaltos. El trato tibio que le da a la Restauración nos pone en la pista; y la solución que reclama para el periodo post-bélico, que aunque tarde se produjo (1975), nos da la certeza de que sabía lo que decía. 


\section{BIBLIOGRAFIA CONSULTADA}

ABELLÁn, José L.: La crisis contemporánea (1875-1936). Madrid, Espasa, 1988.

CARANDE, Ramón: Un vástago tardío de la llustración: José Castillejo (1877-1945) en Galería de Amigos (del mismo autor). Madrid, Alianza Tres, 1989.

CASTILlEJo, José: Guerra de Ideas en España. Madrid, Revista de Occidente, 1976.

CASTILLEJO, José: El Sol, diversos artículos.

CASTILLEJO, David: Fatalidad y porvenir (1913-1937). Epistolario de José Castillejo. Madrid, Editorial Castalia, 1999.

GAMERo, Carmela: Un modelo europeo de renovación pedagógica: José Castillejo. Madrid, CSIC-Instituto de Estudios Manchegos, 1988.

MARTINEZ NADAL, Ramón: El hombre y su quehacer en la Voz de Londres (1940-1945). Madrid, Editorial Casariego, 1998.

PalaCIOS, Luis: José Castillejo. Última etapa de la Institución Libre de Enseñanza. Madrid, Narcea Ediciones, 1979.

VV.AA.: La Junta para Ampliación de Estudios. Revista Arbor n. ${ }^{\circ} 493$, de enero 1987.

VV.AA.: La Junta para Ampliación de Estudios (2.. parte). Revista Arbor n. ${ }^{\circ} 499-500$, de julioagosto, 1987.

VV.AA.: José Castillejo y la política europeísta para la reforma educativa española. Ciudad Real, Diputación de Ciudad Real-Biblioteca de autores y temas manchegos, 1987 (Artículos de I. Gutiérrez Zuloaga, R. Martínez Nadal y A. Romero).

VV.AA.: La Junta para Ampliación de Estudios e Investigaciones Científicas 90 años después. Madrid, CSIC, 1988 (artículos de J. M. Sánchez Ron y V. Cacho Viu). 